\title{
DINÂMICA SAZONAL E OS EFEITOS DAS RESSACAS NAS PRAIAS DE NITERÓI/RJ
}

\author{
CARLA LUIZA DOS SANTOS ${ }^{1}$, MARIA AUGUSTA MARTINS DA SILVA ${ }^{1}$ \\ \& MARCUS VINICIUS SANTORE SALVADOR ${ }^{2}$
}

\begin{abstract}
SEASONAL DYNAMICSANDTHERESULTS OF STORM WAVES UPONTHE BEACHES OF NITERÓI/RJ Beaches are important for the protection of the coastal region against stormy waves. Therefore, beach conservation is fundamental but, contrary to that, beaches and related environments in the sandy barrier are frequently modified by human activity. The aim of this work is to present observations carried on from 1991 to 2002, on the beach dynamics of Niterói (RJ), as a response to seasonal stormy waves. Topographic profiles obtained on the beach and shoreface, pointed out that some parts of the beaches are more vulnerable to stormy waves activity and thus need special attention since problems with urban constructions already exist. These areas are the northwest extreme of Icaraí, both extremes of Piratininga and the northwest and center of Camboinhas beach.
\end{abstract}

Keywords: beach morphodynamics, storm waves and regional geology.

\begin{abstract}
Resumo Praias são ambientes importantes na proteção da região costeira contra a ação das ondas de ressaca. A sua conservação é, portanto fundamental, no entanto, alterações a este ambiente bem como aos ambientes de restinga associados vem sendo cada vez mais frequientes pela ação e ocupação do homem. Neste sentido, este trabalho apresenta observações realizadas de 1991 a 2002 sobre o comportamento das praias de Niterói (RJ), frente à ação sazonal das ressacas. Os perfis topográficos obtidos na praia e face litorânea indicaram que alguns trechos das praias desse litoral precisam de um acompanhamento sistemático, pois são mais vulneráveis às ressacas e já apresentam problemas de destruição de algumas construções urbanas. Tais áreas são o extremo noroeste da praia de Icaraí, os extremos do arco praial de Piratininga e o extremo noroeste bem como o meio do arco praial de Camboinhas.
\end{abstract}

Palavras-chave: morfodinâmica de praia, ressacas e geologia regional.

INTRODUÇÃO O objetivo deste trabalho é analisar a morfodinâmica praial, principalmente durante períodos de ressaca nas praias de Niterói (Fig. 1). Esta é uma região densamente habitada e desde a década de 70 várias áreas costeiras têm sido aterradas o que modifica a morfologia das praias. As praias estudadas, Icaraí (enseada de Jurujuba na baía de Guanabara), Piratininga, Camboinhas e Itaipú (enseada de Itaipú, na região oceânica), possuem dinâmicas distintas. A praia de Icaraí, localizada na margem leste da baía de Guanabara, apresenta baixa dinâmica, enquanto que as praias de Piratininga, Camboinhas e Itaipú, situadas fora da baía de Guanabara, apresentam dinâmica moderada.

As ondas incidentes sobre a enseada de Jurujuba são preferencialmente dos quadrantes S e SW. Segundo Silva et. al. (1999) as praias dessa enseada podem ser divididas em 2 setores, com dinâmicas distintas: o setor 1, onde estão as praias de Boa Viagem, Flexas e Icaraí, apresenta maior dinâmica, com altura média de onda, determinada na arrebentação, de $0,50 \mathrm{~m}$ sob condições normais e de 1,5 $\mathrm{m}$ de altura nos períodos de ressaca; o setor 2, onde estão as praias de São Francisco e Charitas, apresenta menor dinâmica, com altura média de onda de $0,30 \mathrm{~m}$ sob condições normais e entre $0,50 \mathrm{~m}$ e $0,70 \mathrm{~m}$ nos períodos de ressaca. Na enseada de Itaipú as ondas incidentes provêm dos quadrantes SE, S e SW (Gallissaires 1990, apud Bastos 1994). Segundo Gallissaires (1990, apud Bastos 1994) as ondas dos quadrantes SE (de menor energia - construtivas) se difratam pela presença das ilhas da Menina, da Mãe e do Pai e são divergentes quando alcançam a linha de praia. Já as ondas de SW (de ressaca) convergem diretamente sobre a porção centro-oeste da praia de Piratininga. A altura média da onda na praia de Camboinhas/Itaipú sob condições normais é de $1 \mathrm{~m}$, mas podem atingir $3 \mathrm{~m}$ durante ressacas (Santos 2001).

As ondas de ressaca destroem bens públicos e privados em todos os lugares do mundo. Foi realizada uma pesquisa sobre a frequiência e os principais problemas provocados pelas ressacas em nosso litoral registrado ao longo de 107 anos nos arquivos do Jornal do Brasil, O Fluminense, O Globo, e na Fundação Biblioteca Nacional. É importante ressaltar que os dados obtidos são relativos às ressacas mais importantes, o que não impede de terem ocorrido ressacas de menor intensidade ao longo do período observado, porém não registradas (Tabela 1).

As ressacas duram em média 5 dias no nosso litoral segundo os dados levantados. Isto também foi relatado por Carter (1988) em outras partes do mundo. Com essa média confeccionou-se um gráfico que indicou que a maior frequiência das ondas de ressaca ocorre entre os meses de Março e Agosto ao longo desses 107 anos de registro histórico (Fig. 2).

A Diretoria de Hidrografia e Navegação (DHN) classifica a maré na região estudada como do tipo mista, semi-diurna e com amplitudes máximas de até $1,40 \mathrm{~m}$. Segundo Muehe (1989) essa pequena amplitude não favorece a geração de correntes de maré capazes de transportar areia.

Muehe \& Sucharov (1981), utilizando dados de 5 anos de observações da direção e intensidade do vento coletados pela DHN na ilha Rasa, mostraram que os ventos mais frequientes durante o ano são oriundos dos quadrantes NE e E que ocorrem entre Setembro a Fevereiro, e as maiores intensidades médias são apresentadas pelo vento de SW, entre Março a Agosto.

A análise da morfodinâmica praial visa subsidiar o desenvol-

I - Departamento de Geologia, Instituto de Geociências - UFF. Av. Litorânea, s/n - 4 Andar. Cep. 24.210-340 - Niterói - RJ. E-mails: carla@igeo.uff.br, augusta@igco.uff.br

2 - SUBSEA7 - Rua Engenheiro Fábio Goulart, 155. Ilha da Conceição. Cep: 24.050-090 - Niterói - RJ - E-mail: vinicius.salvador@ subsea7.com 
vimento urbano, estabelecer parâmetros de gerenciamento costeiro e a implantação de estruturas de engenharia tais como emissários submarinos, piers, colocação de oleodutos, cabos óticos, etc. Os resultados deste trabalho, realizado ao longo de cerca de 10 anos, permitem entender a dinâmica sazonal dos perfis e identifi-

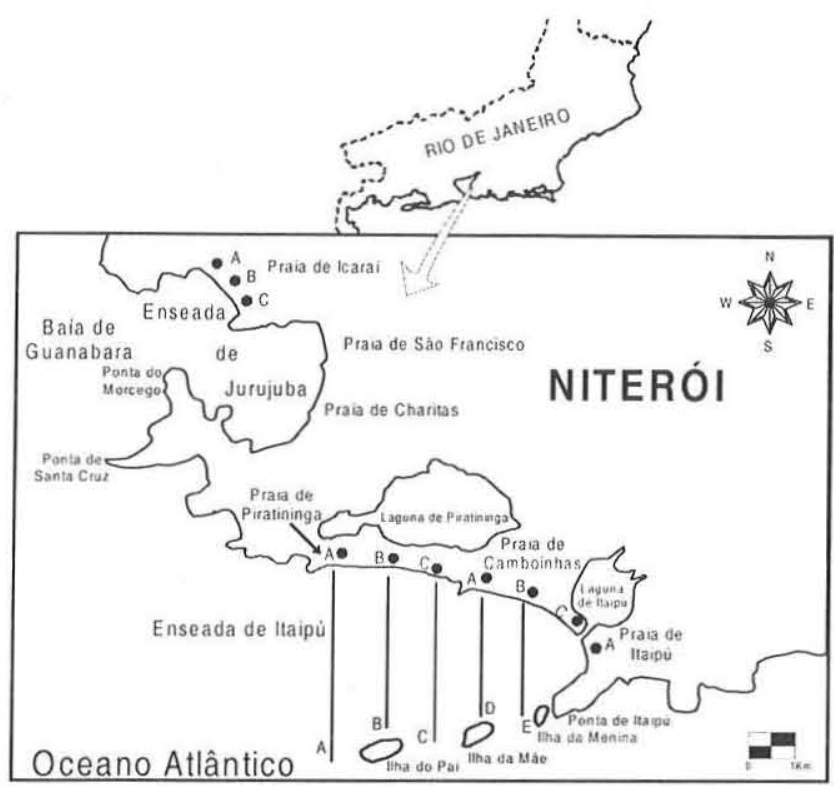

Figura 1 - Localização dos perfis realizados em Niterói (RJ): pontos correspondem aos perfís de praia e as linhas aos perfis da face litorânea. car áreas de maior remoção de areia pelas ondas de ressaca.

MÈTODOS As praias estudadas foram divididas em um ou mais locais de perfilagem, em função de sua extensão e dinâmica (Fig. I e Tabela 2). Após a escolha dos trechos a serem analisados, a topografia praial foi obtida com o método das balizas (Emery 1961) que consiste em realizar perfis perpendiculares à linha de praia que fornecem as variações topográficas da praia no momento da observação. Foram realizados 98 perfís de praia entre os anos de 1991 a 2002, com freqüência sazonal, procurando-se sempre coletar os dados na mesma fase de maré.

Os dados dos 98 perfis de praia foram digitados na planilha do programa GRAPHER 3.1 for Windows ${ }^{\odot}$. As planilhas geraram gráficos que foram editados e superpostos para se compreender a dinâmica e as variações dos perfis em cada estação do ano, bem

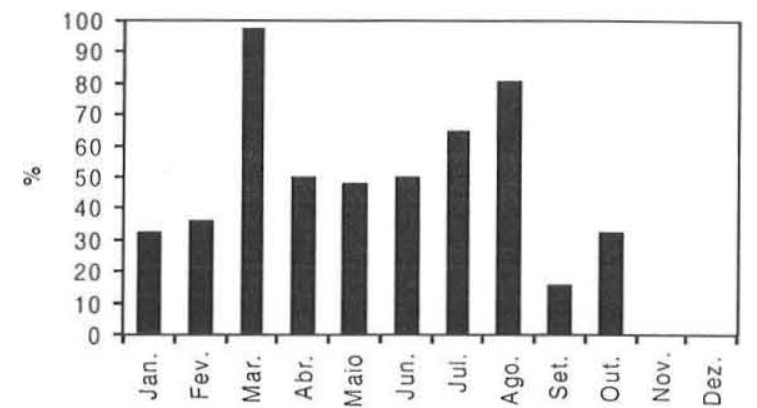

Figura 2 - Frequiência das ressacas entre os anos de 1892 e 1999.

Tabela 1 - Histórico das ressacas registradas no litoral fluminense.

\begin{tabular}{|c|c|}
\hline Dia / Mês /Ano & Descrição \\
\hline $14 / 07 / 1892$ & Cais das barcas do município de Niterói \\
\hline $09 / 03 / 1913$ & Destruição da avenida beira-mar no Rio de Janeiro \\
\hline $14 / 07 / 1921$ & Destruição do calçadão da avenida Atlântica \\
\hline $27 / 10 / 1927$ & Cais das barcas no Rio e em Niterói \\
\hline $11 / 03 / 1958$ & Areias e lixo no calçadão das praias das Flexas e lcaraí \\
\hline $19 /() 4 / 1963$ & Cais das barcas do Rio, Niterói e Paquetá e calçadão de learaí \\
\hline$(07 /(04 / 1966$ & Lixo e areia na orla de Niterói \\
\hline $21 / 05 / 1975$ & Destruição do Postinho da praia da Barra da Tijuca \\
\hline $29 / 07 / 1975$ & Ondas de $2 \mathrm{~m}$ de altura em toda a orla de Niterói \\
\hline $18 / 05 / 1977$ & Destruição da pavimentação Av. Almirante Tamandaré na praia de Piratininga \\
\hline $07 / 07 / 1977$ & Isolamento de pescadores nas ilhas da Cotunduba, Cagarras e Tijucas \\
\hline $21 / 02 / 1978$ & Ondas de $15 \mathrm{~m}$ de altura em toda orla fluminense \\
\hline $28 / 03 / 1974$ & Areias e lixo no calçadão e nas pistas das avenidas litorâneas do Rio de Janeiro \\
\hline \multirow{2}{*}{\multicolumn{2}{|c|}{$\begin{array}{l}03 / 01 / 1980 \\
25 / 08 / 1982\end{array}$}} \\
\hline & \\
\hline $2(0 / 10 / 1982$ & Ondas de 5,0 metros destruíram casas na praia Itaipú \\
\hline $04 / 08 / 1983$ & $\begin{array}{l}\text { Ondas de } 3 \mathrm{~m} \text { de altura destruíram o calçadão da praia de Boa Viagem, na praia das Flexas as ondas chegaram a } 10 \mathrm{~m} \text { de } \\
\text { altura e destruição do calçadão da praia de São Francisco. }\end{array}$ \\
\hline $08 / 03 / 1988$ & Destruição de barcos na Marina da Glória e do late Clube do Rio \\
\hline $13 / 08 / 1988$ & $\begin{array}{l}\text { Ondas de } 4 \text { m de altura na orla do Rio; destruição da Marina da Glória: na praia das Flexas areia, pedras e lixo foram } \\
\text { depositados no calçadão; na praia de Icaraí a tubulação de esgoto em frente rua Miguel de Frias foi destruída: } 300 \mathrm{~m} \text { da } \\
\text { porção oeste do calçadão de Piratininga foi destruída. }\end{array}$ \\
\hline $08 /(03 / 1989$ & Destruição de casas na baía de Sepetiba \\
\hline $26 / 08 / 1992$ & Ondas mataram um pescador no Caminho dos Pescadores (Leme) \\
\hline $01 / 06 / 1997$ & $\begin{array}{l}\text { Destruição da ciclovia do Flamengo e do calçadão de São Conrado; na praia de lcaraí a tubulação de esgoto em frente a } \\
\text { rua Miguel de Frias foi destruída }\end{array}$ \\
\hline $10 / 06 / 1997$ & Destruição de $40 \mathrm{~m}$ do calçadão da praia de São Conrado \\
\hline $30 / 03 / 1998$ & Destruição do emissírio submarino de Ipanema \\
\hline $20 / 03 / 1999$ & Ondas de 3 a $4 \mathrm{~m}$ em toda a orla \\
\hline $01 / 06 / 1999$ & $\begin{array}{l}\text { Destruição do calçadĩo do Gragoatá, da tubulação de esgoto na praia de Icaraí e da porção leste do calçadão da praia de } \\
\text { Piratininga }\end{array}$ \\
\hline $25 /(09 / 1999$ & Deposição de areias nas pistas da avenida Atlântica \\
\hline
\end{tabular}


como o seu comportamento ao longo do arco praial.

DISCUSSÃO DOS DADOS Perfís de praia A praia de Icaraí apresentou, nos seus $1600 \mathrm{~m}$ de extensão, perfis mais estreitos e variáveis entre 25,5 e $64,5 \mathrm{~m}$ no extremo noroeste. O perfil estreito relativo ao verão de 1998 (Fig. 3) resultou de obras para a instalação de nova tubulação de esgoto. $\mathrm{O}$ meio do arco praial e o extremo sudeste apresentaram perfis mais largos e estáveis, de 54 a 81,5 m (Fig. 3) (Santos 2001, Silva et. al. 1999). Observa-se um nítido alargamento da faixa arenosa em direção ao extremo sudeste da praia (Fig. 3). A maior variação morfológica no extremo noroeste da praia, em detrimento aos outros locais analisados, aponta para a maior energia da onda neste trecho. A predominância de areias mais grossas neste trecho do arco também é um reflexo dessa dinâmica (Santos 2001). O levantamento do histórico da ação das ressacas no litoral de Niterói (Tab. 1) mostra que o extremo noroeste tem sido o trecho praial mais vulnerável à ação desses eventos de alta energia (Santos 2001). Constatou-se também que nos períodos de outono e inverno ocorre a retirada de cerca de $50.000 \mathrm{~m}^{3}$ de areia, a qual retorna à praia durante a primavera e o verão devido à ação de ondas construtivas. $\mathrm{O}$ constante alargamento da faixa de areia em direção ao extremo sudeste sugere a ação preferencial da corrente de deriva litorânea em direção a esta porção do arco praial (Santos 2001, Silva et. al. 1999).

A praia de Piratininga, com cerca de $2500 \mathrm{~m}$ de extensão, é a que vem apresentando problemas devido a remoção de areia e destruição do calçadão durante as ressacas (Santos 2001, Bastos \& Silva 1995, Bastos 1994). Atualmente, o extremo oeste do arco de praia apresenta perfis entre $55,5 \mathrm{~m}$ (inverno de 2002) e 70,5 m (verão de 2001), enquanto que, no meio do arco praial, as larguras variam de 56,5 m (inverno de 2002) a 70,5 m (verão de 2001), e o extremo leste apresenta larguras de $59 \mathrm{~m}$ (inverno de 2002) a 76,5 m (verão de 2001) (Fig. 4). Apesar deste trecho a leste da praia estar mais largo, as ressacas vem, com freqüência, destruindo parcialmente o calçadão da praia nos últimos 3 anos (Fig. 5). Comparando as observações atuais com as do início dos anos 90, vemos que o extremo oeste da praia apresentava perfis com largura e cerca de $15 \mathrm{~m}$ a aproximadamente $80 \mathrm{~m}$. Outra característica deste trecho era a ausência de vegetação fixa típica de restinga que ocorria em outros locais da praia (Fig. 6) (Bastos \& Silva 1995, Bastos 1994). No meio do arco praial o comprimento dos perfis variava entre cerca de $19 \mathrm{~m}$ até aproximadamente $70,5 \mathrm{~m}$ e apresentava uma porção de vegetação fixa de 13 m (Fig. 6) (Bastos e Silva 1995 e Bastos 1994). No extremo leste o comprimento variava de 19 m até aproximadamente $70,5 \mathrm{~m}$ e apresentava uma porção de vegetação fixa de 15 m (Fig. 6) (Bastos \& Silva 1995, Bastos 1994).
Muehe (1975) realizou uma série de perfis, com o mesmo método, durante fevereiro de 1974, sempre no meio do arco de praia, e obteve largura média de $51,97 \mathrm{~m}$ para esse trecho no verão, apontando para uma estabilidade do meio do arco de praia de Piratininga.

O arco praial Camboinhas/Itaipú formava um único arco denominado de Itaipú até a década de 70, com 3300 m de extensão. Este foi posteriormente dividido em duas praias, denominadas Camboinhas e Itaipú, em função da abertura do Canal de Itaipú. Os perfis realizados no extremo noroeste da praia de Camboinhas apresentaram variações intensas e marcantes nos períodos de outono e inverno. As larguras dos perfis variaram de 40,5 a 58,5 m no outono e inverno enquanto que, na primavera e no verão, os perfis apresentaram larguras de 46,5 a 61,5 m (Fig. 7) (Santos et al. 2000, Santos 2001). Os perfis realizados no meio do arco praial apresentaram variações também intensas. Nos períodos de outono a largura variou de 51 a $58 \mathrm{~m}$ e no inverno entre 49,5 a $63,5 \mathrm{~m}$. Os perfis realizados na primavera e no verão apresentaram largura de 45 a 52,5 m (Fig. 7) (Santos et. al. 2000, Santos 2001). Os perfis realizados no extremo sudeste se apresentaram sempre mais estreitos: nos períodos de outono as larguras variaram de 34,5 a 40 $\mathrm{m}$, enquanto que os realizados nos períodos de inverno apresentaram larguras de 43,5 a 46,5 m, e os na primavera e verão variaram de 31,5 a 48 m (Fig. 7) (Santos et al. 2000, Santos 2001). Na praia de Itaipú os perfis realizados nos períodos de outono apresentaram larguras de 40 a $58 \mathrm{~m}$, e os realizados no inverno larguras de 56 a 58 $\mathrm{m}$, enquanto que, os dos períodos de primavera e verão apresentaram larguras de 52,5 a 61,5 m (Fig. 7) (Santos 2001, Santos et al. 2000). Constatou-se que nos períodos de outono e inverno o volume médio de areia retirado nesta praia é de cerca de $50.000 \mathrm{~m}^{3}$. Muehe (1975) obteve, em perfis realizados no verão de 1974 no antigo meio do arco praial (englobando Camboinhas e Itaipú), largura média de $51 \mathrm{~m}$, valor semelhante ao encontrado neste trabalho, o que é um indicador de estabilidade no que diz respeito ao retorno das areias e alargamento da praia no verão.

O comportamento distinto do arco praial de Camboinhas e Itaipú, principalmente durante períodos de ressaca deve-se à incidência e energia da onda diferenciada ao longo da praia. As ondas de SW atingem com maior energia o extremo noroeste e o meio do arco praial onde provocam intensas variações morfológicas, com estreitamento da faixa de areia emersa, inclusive alcançando a vegetação de restinga, como na ressaca de maio-junho de 1999.

Perfís da face litorânea A relação dos perfis emersos com os submarinos da face litorânea (shoreface) é importante no sentido de apontar tendências erosivas para a linha de costa. Os cinco perfís submarinos obtidos na enseada de Itaipú (Salvador \& Silva

Tabela 2 - Localização dos perfis nas praias estudadas.

\begin{tabular}{|c|c|c|c|c|}
\hline \multicolumn{5}{|c|}{ PRAIA DEICARAÍ } \\
\hline \multicolumn{2}{|l|}{ Perfil A } & \multicolumn{2}{|c|}{ Perfil B } & Perfil C \\
\hline \multicolumn{2}{|c|}{$\begin{array}{l}\text { Extremo noroeste da praia } \\
\text { aproximadamente em frente à rua } \\
\text { Alvares de Azevedo. } \\
\text { Coordenadas UTM: } 0692150-746554\end{array}$} & \multicolumn{2}{|c|}{$\begin{array}{l}\text { Meio do arco praial aproximadamente } \\
\text { em frente a rua Lopes Trovão. } \\
\text { Coordenadas UTM: } 0692708-746495\end{array}$} & $\begin{array}{l}\text { Extremo sudeste da praia } \\
\text { aproximadamente em frente à rua } \\
\text { Comendador Queiroz. Coordenadas } \\
\text { UTM: } 0693220-746418\end{array}$ \\
\hline \multicolumn{5}{|c|}{ PRAIA DE PIRATININGA } \\
\hline \multicolumn{2}{|l|}{ Perfil A } & \multicolumn{2}{|c|}{ Perfil B } & Perfil C \\
\hline \multicolumn{2}{|c|}{$\begin{array}{l}\text { Extremo oeste em frente à rua Rubens } \\
\text { Teixcira Rosado. } \\
\text { Coordenadas UTM: } 0694457 \cdot 746007\end{array}$} & \multicolumn{2}{|c|}{$\begin{array}{l}\text { M cio do arco praial (em frente à Rua } \\
\text { João Tavares). } \\
\text { Coordenadas UTM: } 0696247 \cdot 745987\end{array}$} & $\begin{array}{l}\text { Extremo leste (em frente à rua Joẫo } \\
\text { Gomes da Silva). } \\
\text { Coordenadas UTM: } 0696839-745960\end{array}$ \\
\hline \multicolumn{4}{|c|}{ PRAIA DE CAMBOINHAS } & PRAIA DE ITAIPÚ \\
\hline Perfil A & & Perfil B & Perfil C & Perfil A \\
\hline $\begin{array}{l}\text { Extremo noroeste. } \\
\text { Coordenadas UTM: } 0698420 \\
-745967 \text {. }\end{array}$ & $\begin{array}{l}\text { Meio do } \\
\text { Coorden } \\
-745938\end{array}$ & $\begin{array}{l}\text { arco praial. } \\
\text { das UTM: } 0699423\end{array}$ & $\begin{array}{l}\text { Extremo sudeste. } \\
\text { Coordenadas UTM } \\
(0700091-745900 .\end{array}$ & $\begin{array}{l}\text { Extremo noroeste. } \\
\text { Coordenadas UTM: } 0700240 \\
-745870\end{array}$ \\
\hline
\end{tabular}




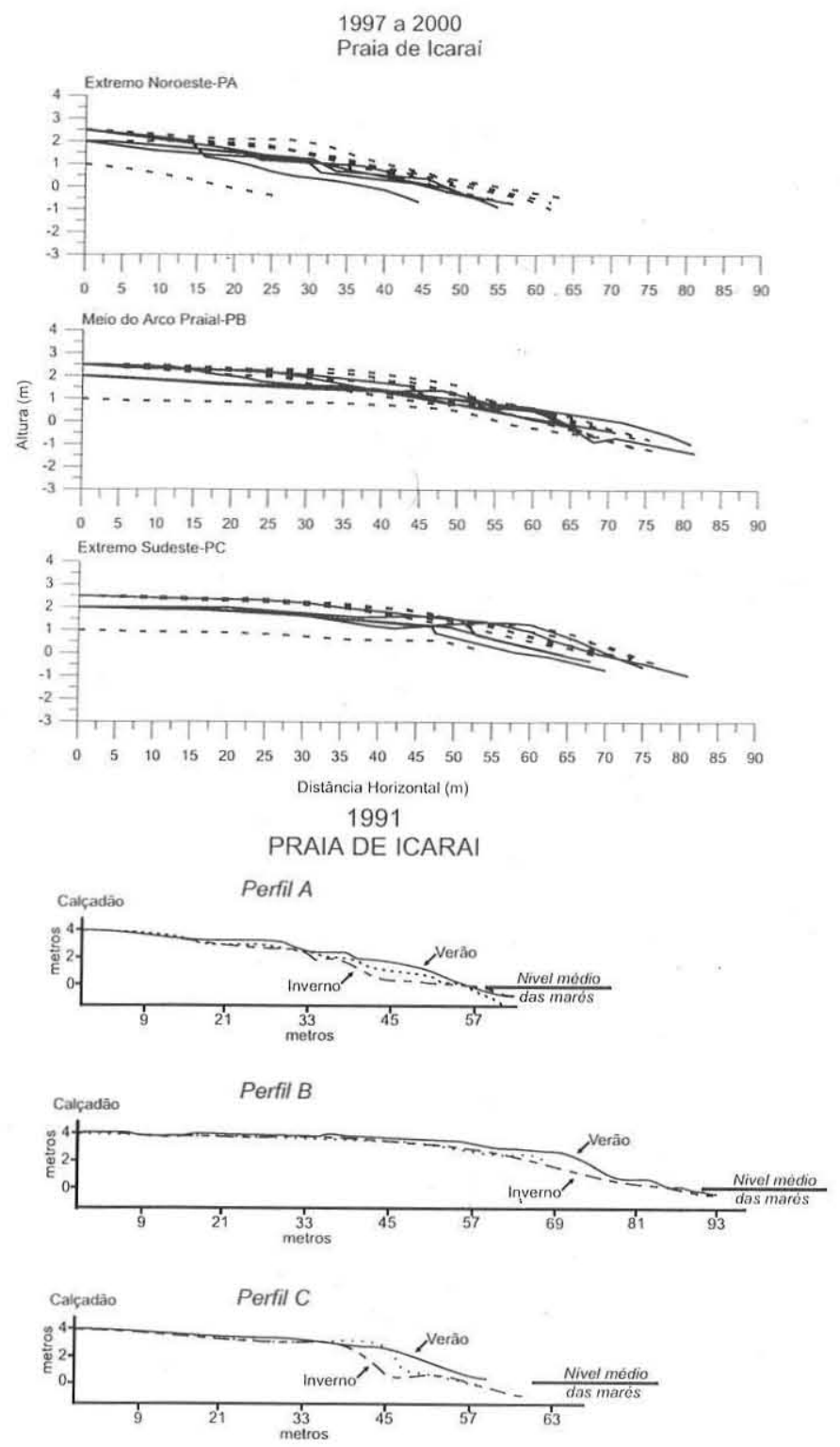

Figura 3 - Perfís da praia de Icaraí: parte superior da figura apresenta os perfis realizados entre 1997 e 2000 (Santos 2001) e a parte inferior mostra os perfis de 1991 (Silva et al. 1999). As linhas cheias correspondem aos perfis realizados no outono $e$ no inverno, enquanto que as linhas tracejadas correspondem aos perfis realizados na primavera e no verão.

2002, Salvador 1999) indicam que a face litorânea superior (dos 3 aos $16 \mathrm{~m}$ aproximadamente) é íngreme, côncava e com gradiente de 1:90. Os perfis mais íngremes são os localizados à oeste da praia de Piratininga e no meio do arco praial de Camboinhas (Fig. 8). Tais características morfológicas de face litorânea são semelhantes àquelas observadas na região submarina da costa de Delaware (E.U.A.) onde historicamente vem ocorrendo erosão de praia (Niedoroda et. al. 1985).

Muehe (1989) em trabalho sobre a estabilidade da linha de costa entre a cidade do Rio de Janeiro e Cabo Frio, apontou que o extremo oeste da praia de Piratininga, bem como o extremo leste desse arco praial podem ser categorizados como uma zona de risco de "cautela"; o restante da praia de Piratininga e todo o arco

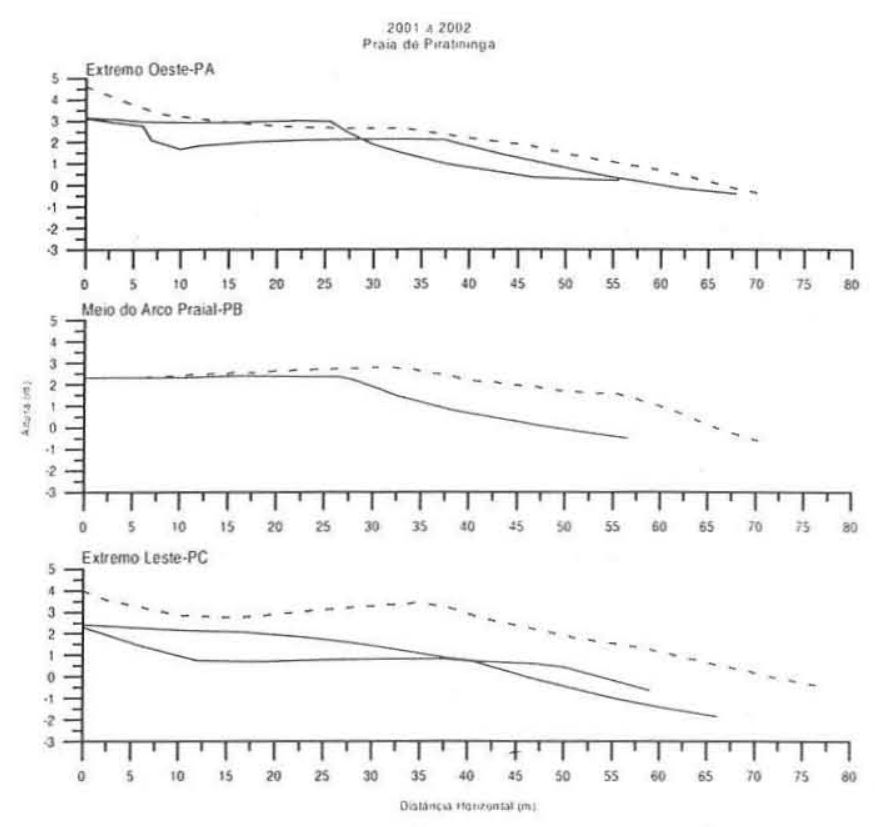

Figura 4 - Perfis de praia em Piratininga de 2001 a 2002. As linhas cheias correspondem aos perfis realizados no outono $e$ no inverno, enquanto que as linhas tracejadas correspondem aos perfis realizados na primavera e no verão.

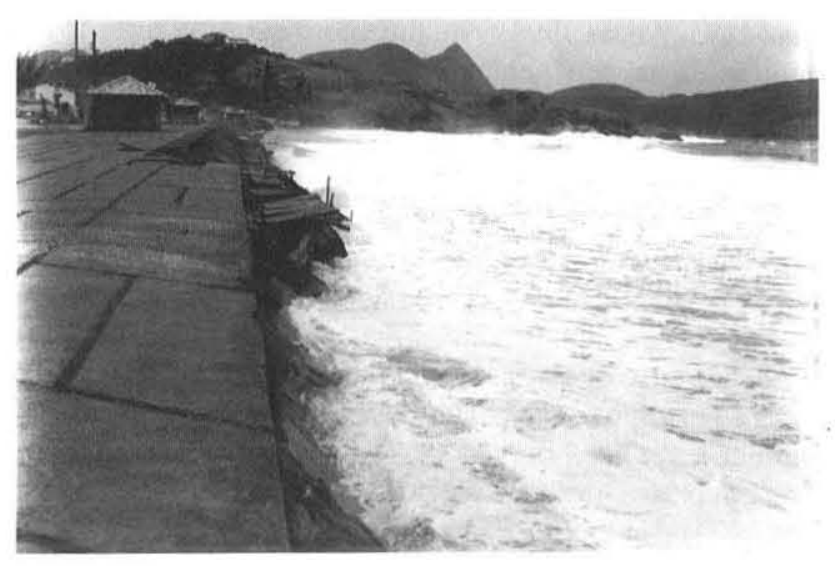

Figura 5 - Ondas de ressaca causaram destruição do calçadão do lado leste da praia de Piratininga em I de junho de 1999.

praial Camboinhas-Itaipú foi considerado como seguro. O perfil 7 coletado por Muehe (1979) no meio do arco de Piratininga e o perfil 8 no de Camboinhas/Itaipú estão localizados aproximadamente na mesma região dos perfis aqui apresentados como B e E respectivamente. O perfil $\mathrm{B}$ de Piratininga não apresenta o degrau topográfico à cerca de $10 \mathrm{~m}$ de profundidade como aparece no perfil 7 de Muehe (1979), estando o fundo agora mais plano e raso. O perfil E em Camboinhas está mais íngreme e escavado do que o perfil 8 de Muehe (1979).

Os dados aqui apresentados corroboram a necessidade de se considerar com cautela a extremo oeste da praia de Piratininga; porém o extremo a leste vem apresentando também problemas sérios de remoção de areia e destruição do calçadão, assim que a área sob cautela tem se expandido e hoje atinge uma extensão bem maior do que aquela indicada por Muehe (1989). Consideramos 


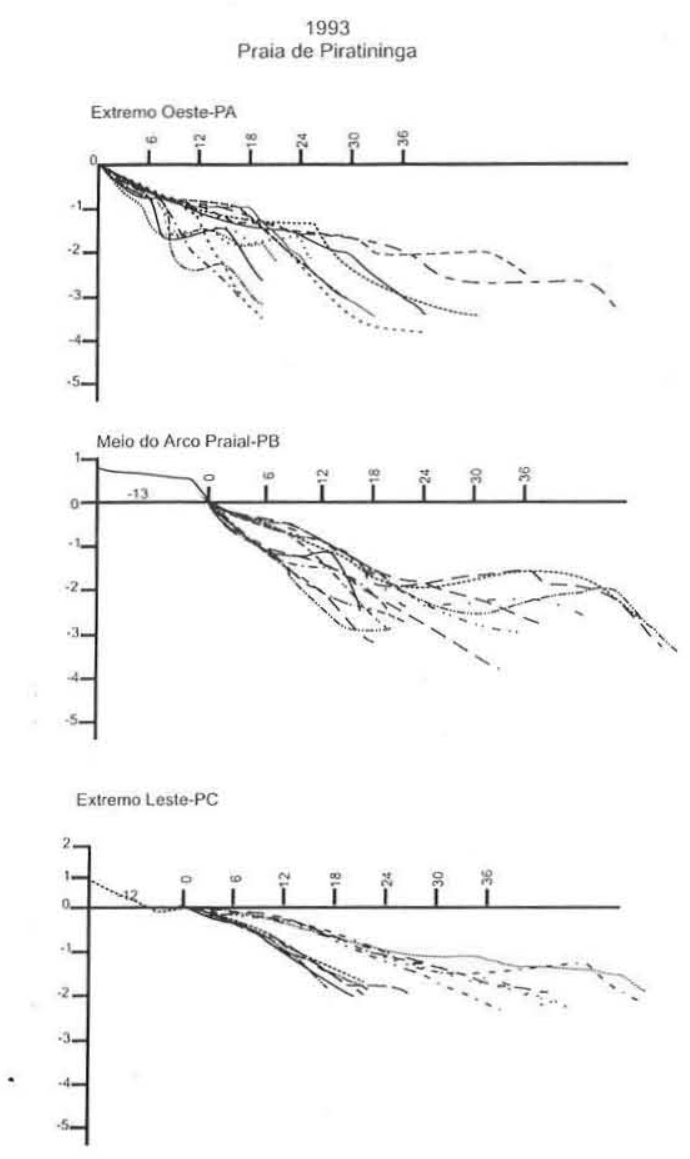

Figura 6-Perfís realizados na praia de Piratining a nos meses de Abril à Novembro de 1993 acompanhando as passagens das frentes frias (Bastos 1994).

assim ambas as pontas do arco de Piratininga como vulneráveis ou com potencial para sofrer erosão decorrente da ação antropogênica. $\mathrm{O}$ arco de praia Camboinhas/Itaipú, considerado seguro por Muehe (1989), é agora também vulnerável, pois marcas de erosão foram deixadas pela ressaca de 1999, tanto no extremo noroeste como no centro do arco (Fig. 9). O perfil é reconstruído pelas ondas de tempo bom, porém a crescente urbanização e descaracterização dessa praia a tornam vulnerável à ação das ondas de ressaca.

Assim, é possível identificar os locais das praias mais vulneráveis à ação das ondas de ressaca no litoral de Niterói: o extremo noroeste da praia de Icaraí, os extremos oeste e leste da praia de Piratininga e o extremo noroeste e o meio do arco praial de Camboinhas (Fig. 9). É importante o acompanhamento da ação das ressacas neste litoral, bem como o cuidado na ocupação e na execução das obras costeiras que possam impedir a circulação de areias na praia.

CONCLUSÕES As observações realizadas ao longo de cerca de 10 anos sobre a dinâmica das praias de Niterói permitiram a compreensão e identificação dos problemas existentes.

O extremo noroeste da praia de Icaraí apresentou-se sempre mais estreito e variável em todas as estações, enquanto o meio do arco praial e o extremo sudeste apresentaram sempre perfis mais largos e estáveis, com características mais deposicionais. Esta diferenciação está relacionada à maior atuação das ondas de res-

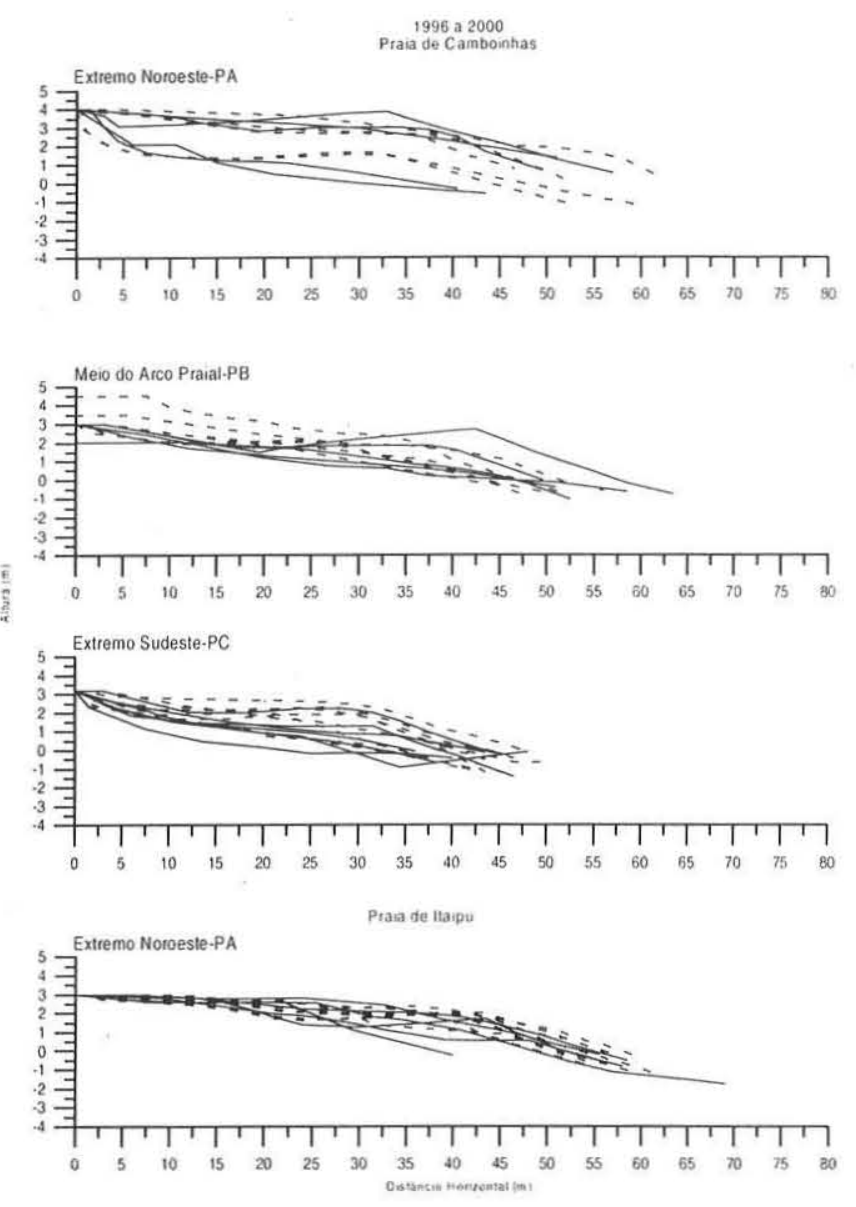

Figura 7 - Perfis de praia de Camboinhas e de Itaipú de 1996 a 2000. As linhas cheias correspondem aos perfis realizados no outono e no inverno, enquanto que as linhas tracejadas correspondem aos perfis realizados na primavera e no verão.

saca no extremo noroeste e a uma ação discreta da corrente de deriva litorânea para sudeste.

A praia de Piratininga apresenta-se, atualmente, mais larga no extremo oeste e estreita no extremo leste, onde o calçadão vem sendo destruído pelas ondas de ressaca. No entanto, as ondas de ressaca também podem atuar no extremo oeste, estreitando a faixa de areia e provocando a destruição parcial do calçadão. Assim ambas extremidades apresentam problemas decorrentes da remoção de areia durante as ressacas.

A praia de Camboinhas apresenta no seu extremo sudeste perfis mais estreitos em todas as estações; no meio do arco praial e no extremo noroeste a praia de Camboinhas apresentou-se mais larga, porém mais dinâmica. O perfil do extremo noroeste da praia de Itaipú se comportou de modo clássico: mais estreito e íngreme nos períodos de outono-inverno e mais largo nos períodos de primavera-verão. Esta diferenciação do comportamento dos perfis ao longo do arco praial está relacionada, principalmente, à ação das ondas de ressaca provenientes de SW que atingem mais intensamente a praia a partir do meio do arco praial em direção ao extremo noroeste da praia de Camboinhas. Outro processo responsável pela diferenciação da largura dos perfis é a corrente de deriva litorânea. O comportamento das faixas de areia dos extremos noroeste da praia de Itaipú e sudeste da praia de Camboinhas 


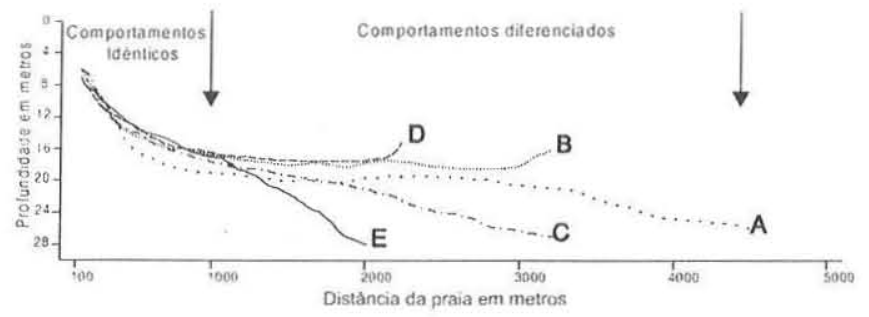

Figura 8 - Perfís da face litorânea da Enseada de Itaipú (localização na Fig. 1).

aponta para a ação da corrente de deriva litorânea de Itaipú para Camboinhas devido às freqüentes ondas de sul. O molhe do Canal de Itaipú bloqueia o transporte de areia para NW fazendo com que o perfil SE da praia de Camboinhas fique sempre mais estreito.

O processo mais importante na remoção de areia das praias estudadas é aquele relacionado à atividade das ondas de ressaca. As ressacas ocorrem mais freqüentemente nos períodos de outono e inverno, mas podem ocorrer ressacas de menor intensidade em qualquer época do ano. O histórico da ocorrência de ressacas no litoral fluminense sugere uma frequiência de aproximadamente 20 anos para as ressacas mais violentas. A frequiência de 20 anos também foi sugerida por meteorologistas que vêem estudando tal fenômeno no hemisfério norte (Gray 2001). Esta tendência, combinada à interferência cada vez mais intensa do homem sobre o ambiente litorâneo, faz com que as áreas mais vulneráveis à ação das ondas de ressaca mereçam uma atenção e acompanhamento especial. Como resultado deste trabalho, constatamos que tais áreas são: o extremo noroeste da praia de Icaraí, os extremos oeste

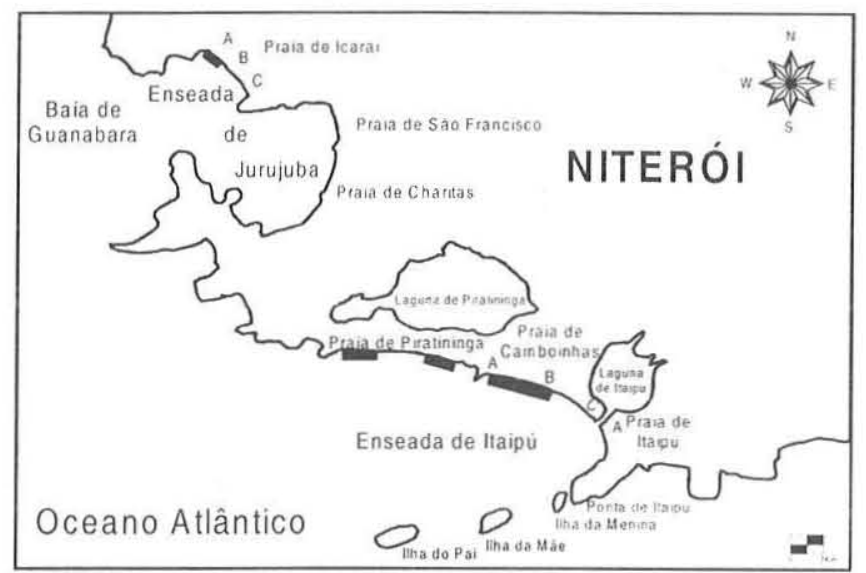

Figura 9 - Localização das áreas mais vulneráveis à ação das ressacas nas praias de Niterói.

e leste da praia de Piratininga e o extremo noroeste bem como o meio do arco praial de Camboinhas.

Agradecimentos À CAPES e à FAPERJ pelas bolsas de mestrado e apoio técnico, respectivamente. Aos professores e funcionários do Departamento de Geologia da UFF. Àos alunos Alípio Pereira, André Luiz Carvalho da Silva, Anídio Corrêa, Carlos Lacerda, Chester Mariano, Fernando Fridlund, George Uller, Hugo Sardenberg Jr., Lara Varoveska, Ricardo Menezes e Ricardo Nascimento. Aos revisores da RBG pelas sugestões ao manuscrito.

\section{Referências}

Bastos A.C. \& Silva C.G. 1995. Study of morphological variations from beach profiles in Piratininga Beach, Niterói-RJ, Brazil. In: ABEQUA, Congr. Assoc. Bras. de Est. do Quarternário, 5, Anais, ps.205-210.

Bastos A.C. 1994. Estudos da variação morfológica a partir de perfis de praia em Piratininga, Niterói, RJ, Brasil. Monografia, Instituto de Geociências, Universidade Federal do Rio de Janeiro, 121 p.

Carter R.W.G. 1988. Coastal environment: introduction to the physical, ecologycal and cultural systems of coastlines. Academic Press, London, $617 \mathrm{pp}$.

Diretoria de Hidrografia e Navegação (DHN) - Tábuas de Marés para o Porto do Rio de Janeiro.

Emery K.O. 1961. A simple method of measuring beach profiles. Limnol. Oceanogr:, 5:90-93.

Gray W. 2001. Hyper hurricanes. 5p. http://www.discovery.com/stories/ science/hurricanes/future.html

Muehe D. 1975. Análise ambiental no sistema costeiro sul-oriental do Estado Do Rio De Janeiro. Dissertação de Mestrado. Instituto de Geociências, Universidade Federal do Rio de Janeiro, $111 \mathrm{p}$.

Muehe D. 1979. Sedimentology and topography of a high energy coastal environment between Rio de Janeiro and Cabo Frio. Anais Acad. Bras. Ciênc. 51:473-481.

Muehe D. \& Sucharov E.C. 1981. Considerações sobre o transporte de sedimentos na plataforma continental nas proximidades das ilhas Maricás, RJ. Ancuis Acad. Bras.de Ciên., pp. 238-246.
Muehe D. 1989. The coastline between Rio de Janeiro and Cabo Frio. In: Symp. Coastal and Ocean Management, 6. Charleston (USA), p. 13.

Niedoroda A.W., Swift D.J.P., Hopkins T.S. 1985. The shoreface. In: R.A. Davis Jr: (ed.), Coastal sedimentary environments. SpringerVerlag. New York, pp: 533-624.

Salvador M.V.S. \& Silva M.A.M. 2002. Morphology and sedimentology of the Itaipú Embayment - Niterói/RJ. Anais Acad. Bras. Ciênc. 74:127-134.

Salvador M.V.S. 1999. Morfologia e sedimentologia da enseada de ItaipúNiterói/RJ. Dissertação de Mestrado, Instituto de Geociências, Universidade Federal Fluminense, p. 38.

Santos C.L. 2001. Dinâmica sazonal e os efeitos das ressacas nas praias de Niteroi (Rio de Janeiro). Dissertação de Mestrado, Instituto de Geociências, Universidade Federal Fluminense, p. 151.

Santos C.L., Silva M.A.M., Mariano C.N. 2000. Os efeitos das ressacas nas praias de Camboinhas e Itaipú, região oceânica de Niterói/RJ. In: Simp. Bras. Praias Arenosas, 1, Resumo Expandido p. 82-83.

Silva M.A.M., Resende M.C.C.M., Santos C.L.. 1999. Um estudo sobre a dinâmica das praias de Niterói (Baía de Guanabara, RJ). Anais da Acad. Bras. de Ciênc., 71(4II):962-967.

Manuscrito A-1409

Recebido em 10 de fevereiro de 2003 Revisão dos autores em 08 de maio de 2004 Revisão aceita em 25 de maio de 2004 